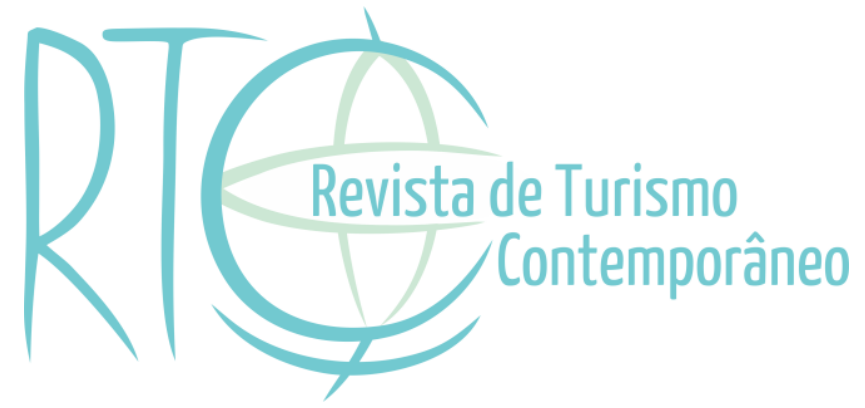

\title{
Gestão do turismo em tempos de crises e vulnerabilidades
}

Management of tourism in times of crises and vulnerabilities

Sinthya Pinheiro Costa

Professora do Instituto Federal da Paraíba - IFPB, João Pessoa/PB, Brasil

E-mail: sinthyapcosta@gmail.com

Kerlei Eniele Sonaglio

Professora da Universidade Federal do Rio Grande do Norte - UFRN, Natal/RN, Brasil E-mail: kerlei@ufrnet.br 


\section{RESUMO}

As constantes crises de ordem econômica, política, social, ambiental tem acometido diversos países e afetam diretamente a gestão do turismo. Na busca pela superação das adversidades, as organizações e gestores que apresentam características resilientes tendem a preservar e restaurar suas estruturas e funções essenciais após os eventos perturbadores. Desta forma, com vistas a compor um documento de apoio para os debates sobre a gestão do turismo em tempos de crise e em situações de vulnerabilidade, se realizou um levantamento bibliográfico e eletrônico para identificar textos científicos e também de organismos internacionais que clarificassem os conceitos da resiliência e sua utilização no turismo. É preciso: a) perseguir as indicações do Tourism Resilience Committee para mitigação de riscos relacionados ao turismo; b) diagnosticar a capacidade resiliente de um gestor do turismo (metodologia SOBRARE) visando desenvolver características capazes de tornar os sujeitos mais preparados para enfrentar e superar as adversidades; c) incorporar no processo de planejamento e gestão de cidades turísticas as indicações da Campanha da ONU para tornar as cidades resilientes.

Palavras-chave: Turismo. Gestão. Crises. Vulnerabilidade. Resiliência.

\section{ABSTRACT}

The constant economic, political, social and environmental crises have reached numerous countries and directly affect tourism management. In the wake of disruptive events resilient organizations and managers tend to preserve and reestablish their essential business and duties in order to overcome adversities. With the aim of constructing a document to contribute to debates surrounding tourism management in times of crisis and in vulnerable situations, we carried out a literature review of scientific papers and international bodies that have classified the concepts of resilience as it is related to tourism. Our findings point to a necessity to: a) pursue the Tourism Resilience Committee guidelines to mitigate tourism-related risks; $b$ ) diagnose the resilience capacity of a tourism manager (SOBRARE method) with the aim of developing characteristics to contribute to better preparing these managers to face and overcome adversities; c) incorporate the suggestions from the UN Campaign to turn cities more resilient into the planning and managing process of tourist cities.

Keywords: Tourism. Management. Crises. Vulnerability. Resilience. 


\section{INTRODUÇÃO}

Desenvolver ações que promovam a resiliência, num contexto de crise ou de vulnerabilidade, figura como uma opção salutar visando à antecipação e/ou previsão destas ocasiões, bem como uma possibilidade para reverter as consequências das crises. Isto porque a resiliência é um constructo dinâmico que envolve tanto a capacidade do indivíduo de adaptar-se ao ambiente externo quanto do ambiente em modificar-se com o indivíduo (Sordi, Manfro \& Hauck, 2011). Neste contexto, qualificar um sistema turístico, uma comunidade ou uma sociedade como "resiliente" significa, entre outros aspectos, dizer que diante de uma situação adversa ela é capaz de resistir, absorver, acomodar-se, adaptar-se e reconstituir-se em tempo e modo adequados, preservando e restaurando suas estruturas e funções essenciais.

De todo modo, é preciso considerar que muitas "vulnerabilidades" - como as de ordem social, econômica e ambiental - as quais as populações estão expostas, decorrem do crescimento veloz e desordenado das cidades que se vergam aos efeitos da inércia/ineficiência do planejamento e da gestão produzindo impactos, geralmente, irreversíveis. Em outras situações, estas vulnerabilidades são reduzidas e/ou controladas por meio de ações resilientes. A "resiliência" como abordagem e como guia orientativo de ações gerenciais para o turismo manifesta-se como uma opção que figura como pauta neste artigo, de natureza reflexiva, que tem como ponto de partida a iminente utilização do conceito da resiliência pelo turismo, como forma de redução e superação de eventos adversos sofridos pela (e na) atividade.

Parte-se então dos primeiros estudos que culminaram com a adoção da resiliência para o desenvolvimento urbano, como proposto nas ações apresentadas no Marco de Ação de Hyogo (MAH) que resultaram em um acordo entre 168 países que se comprometeram em agir em cinco frentes prioritárias de ação. Estas ações estão relacionadas com: a redução de risco de desastre deve ser uma prioridade; conhecer o risco e adotar medidas; desenvolver mais compreensão e conscientização; reduzir o risco; fortalecer a preparação em desastres para uma resposta eficaz, em todos os níveis.

A partir do entendimento do conceito de resiliência e dos debates dos países acerca da necessidade de incorporação da mesma nas ações de redução de riscos, é elaborada a metodologia "Como Construir Cidades Mais Resilientes: Guia para Gestores Públicos Locais" pelo Escritório Geral das Nações Unidas para Redução de Riscos de Desastres (UNISDR) no ano de 2012. No ano de 2015, finalizou o prazo inicial para implementação do MAH, tendo sido realizada a III Conferência Mundial sobre a Redução do Risco de Desastres, onde foi adotado pelos países membros da ONU o Marco de Sendai para a Redução do Risco de 
Desastres 2015-2030, tendo os Estados reiterado o compromisso com a redução de desastres e com o aumento da resiliência (UNISDR, 2015). Em decorrência desse novo acordo global, foi percebida a necessidade de reformulação da campanha "Construindo Cidades Resilientes" que culminou com a elaboração do guia supracitado, pretendendo incorporar a essa campanha as novas diretrizes estabelecidas no Marco de Sendai.

De acordo com o Ministério da Integração Nacional (2016, n/p) "busca-se uma maior coordenação interfederativa e o alinhamento da Campanha com as políticas públicas federais, em sede de gestão dos riscos de desastre”. Ainda segundo o Ministério, o Brasil é o país com maior número de municípios inscritos na campanha que tem uma abrangência mundial. $\mathrm{A}$ figura 01 apresenta os países que adotaram a campanha das cidades resilientes e a quantidade de cidades de cada um. Nela é possível perceber que 359 cidades brasileiras aparecerem como integrantes/ parceiras da campanha Cidades Resilientes, sendo o país com maior número de participantes. São exemplos de cidades que aderiram a campanha no Brasil: Recife (PE), Blumenau (SC), São Paulo (SP), Curitiba (PR), todas destinos turísticos consolidados. É preciso ressaltar que onde aparece a quantidade de 459, próximo a França e Itália representa não só a quantidade desses países, mas de toda a região que engloba além desse dois países, a Alemanha, Áustria, Hungria, Sérvia entre outros nas proximidades.

A figura 01 reafirma a importância que tem sido dada à resiliência, não só em âmbito internacional, como também nacional. Entender que este é o caminho para redução de desastres, para que as cidades estejam mais preparadas para enfrentar as vulnerabilidades e para mitigar os impactos que eventos adversos ocasionam, já reitera o quão importante é a resiliência para quem a adota. Cabe ressaltar que este não tem sido um esforço pontual, isolado de algumas cidades, mas uma união de países que entenderam que a resiliência é o caminho e afirmam isso quando assinam um acordo para continuar adotando essa perspectiva para a gestão das cidades. 


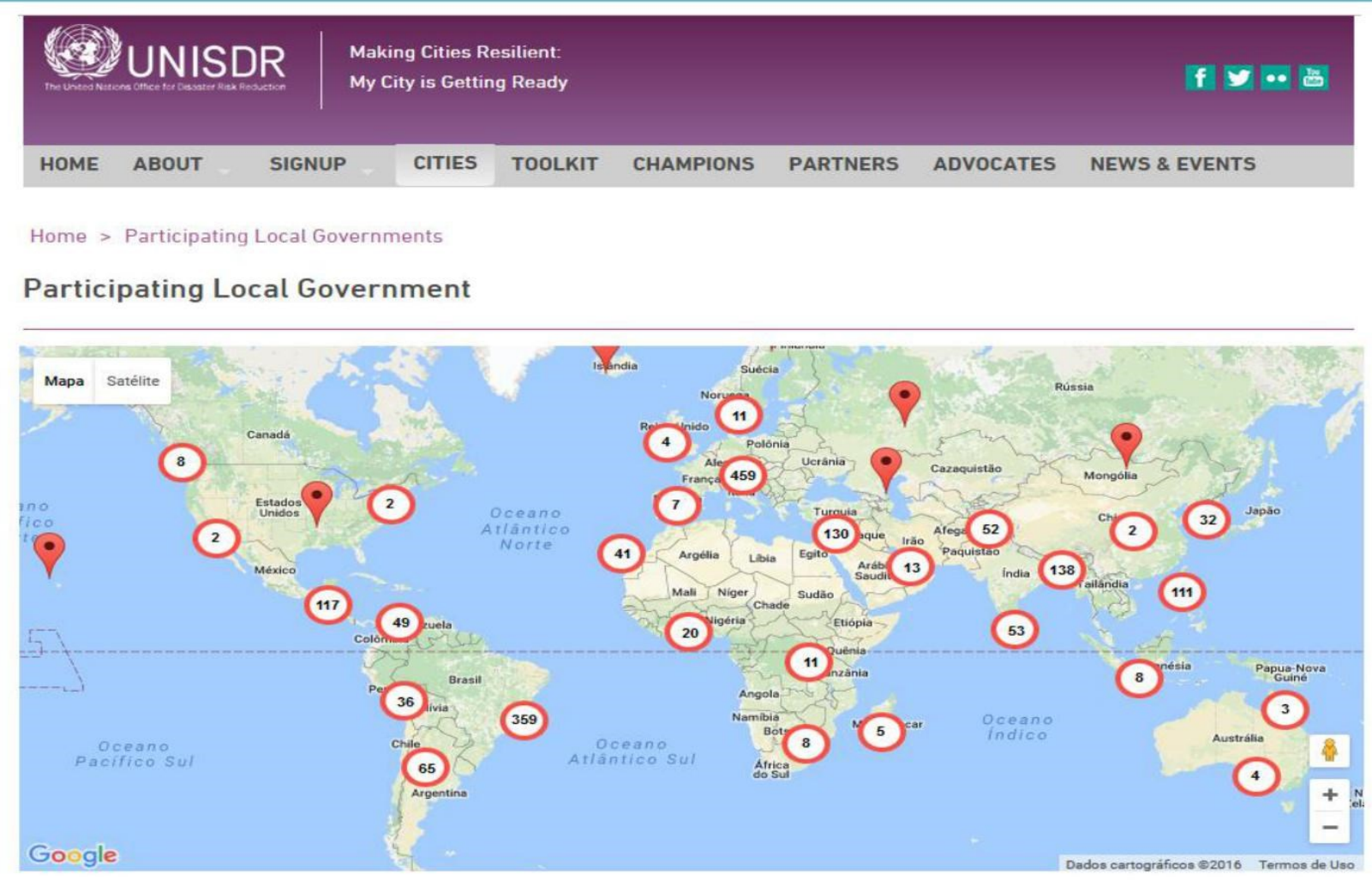

Figura 01: Países que participam da campanha Cidades Resilientes

Fonte: UNISDR, 2016.

No tocante ao turismo, em 2008, durante a $84^{\mathrm{a}}$ Sessão do Conselho Executivo da OMT em Madri/Espanha, foi estabelecido o Comitê de Resiliência do Turismo (TRC Tourism Resilience Committee) como forma de resposta à recessão econômica (AJONU, 2012). Tal comitê é parte do programa de resiliência para o desenvolvimento do turismo proposto pela OMT e tem como responsabilidade "assists members to assess and mitigate risks related to tourism. Furthermore, to develop, plan and implement crisis management systems that will reduce the impact of and assist in the recovery from crises, the activities and projects are guided by the relevant provision in the Global Code of Ethics for Tourism" (UNWTO, 2016, n/p).

A prerrogativa de mitigação dos impactos relativos ao turismo e a necessidade de desenvolver, planejar e implementar um sistema de gerenciamento de crise é o que conduz este comitê. É importante salientar que a OMT, quando cria este comitê em 2008, já entende que a resiliência é o caminho para o turismo na contemporaneidade. Em um cenário mundial, onde os destinos não investem (ou investem pouco) em planejamento, gestores são (re)conduzidos a ocupar cargos públicos por acordos políticos ou sociais, o turismo vai se delineando imerso em crises de diversas ordens.

Embasado na perspectiva mundial de inserção da resiliência no contexto de redução de desastres, identificou-se a necessidade de aprofundar os estudos em relação ao estado da arte da resiliência e do turismo. Todavia, as autoras não possuem a pretensão de apresentar 
questões conclusivas sobre as temáticas em tela, mas sim, compor um documento de apoio para os debates sobre a gestão pública do turismo em tempos de crise e em situações de vulnerabilidade.

\section{REFERENCIAL TEÓRICO}

\subsection{A RESILIÊNCIA}

Primordialmente, o conceito de resiliência estava associado à área da física e tinha relação com a capacidade de um determinado material absorver tensões sem apresentar deformidades. Por isso, as explicações científicas iniciais sobre a resiliência preocupavam-se em demonstrar a "resistência" dos materiais, tendo como referência as suas regiões elásticas e plásticas. Nas ciências exatas, o termo "resiliência" se referia aos estudos sobre resistência dos materiais e já era usado desde o início do século 19, quando o físico e médico inglês Thomas Young (Timoshenko, 1953) publicou sua obra sobre a noção de módulo de elasticidade.

Posteriormente, em 1974, o psiquiatra infantil Elwyn James Anthony desenvolveu sua pesquisa sobre o estudo da resiliência para os casos relacionados à saúde e objetivou investigar a vulnerabilidade de crianças filhas de pais esquizofrênicos (Miguel, 2012). Foi a partir deste momento que a questão da resiliência ultrapassou os limites disciplinares da física. Em tal estudo, as diferentes reações percebidas nas crianças culminaram com a utilização do termo "resiliência" designando a capacidade do indivíduo afetado pelo estresse ou pela adversidade, em superá-lo e fortalecer-se.

Diante destas vertentes de estudo sobre a resiliência, Tavares (2001) considerou que a resiliência pode ser compreendida sob três pontos de vista:

a) No enfoque físico: qualidade de resistência de um material ao choque, à tensão, à pressão, ao qual lhe permite voltar, sempre que for forçado ou violentado, à sua forma ou posição inicial (por exemplo, uma barra de ferro, uma mola ou elástico);

b) No enfoque médico: capacidade de resistência do sujeito a uma doença, infecção, intervenção, por si próprio ou com a ajuda de medicamentos;

c) No enfoque psicológico: capacidade das pessoas (individualmente ou em grupo) de resistirem a situações adversas sem perder o seu equilíbrio inicial, isto é, a capacidade de acomodar-se e equilibrar-se constantemente. 
Ao estudarem as origens do conceito de "resiliência" em Psicologia Brandão, Mahfoud \& Gianordoli-Nascimento (2011) constataram que pesquisadores de várias partes do mundo se apropriaram do tema estudando-o a partir de diferentes perspectivas. Ojeda (2004) e Fantova (2008 apud Brandão, Mahfoud \& Gianordoli-Nascimento, 2011) consideraram que tais perspectivas podiam ser compreendidas em 3 correntes, a saber:

1) Norte-americana ou anglo-saxônica: corrente mais pragmática e mais centrada no indivíduo e que toma como avaliação da resiliência dados observáveis e quantificáveis, comumente com enfoque behaviorista ou ecológico transacional. Neste caso, a o estudo da resiliência surge como produto da interação entre o sujeito e o meio em que está inserido;

2) Europeia: corrente de perspectiva ética, mais relativista e com enfoque comumente psicanalítico, tomando a visão do indivíduo como relevante para a avaliação da resiliência, onde a resposta do sujeito às adversidades transcende os fatores do meio e é "tecida" a partir da dinâmica psicológica do indivíduo, o que possibilita uma narrativa íntima e uma narrativa externa sobre a própria vida;

3) Corrente latino-americana: corrente mais comunitária, enfocando o social como resposta aos problemas do sujeito em meio às adversidades.

Mesmo diante das distintas correntes mencionadas, há também, entre pesquisadores anglo-saxões e os falantes de línguas latinas, diferenças na maneira de entender e apresentar as origens do tema e diferenças em suas concepções de resiliência (Brandão, Mahfoud \& Gianordoli-Nascimento, 2011), uma vez que os pesquisadores falantes de línguas latinas (incluindo os brasileiros) apontam que o termo/conceito "resiliência" teria sido tomado das ciências exatas - mais especificamente do campo da resistência dos materiais - enquanto os pesquisadores precursores do $\backslash$ tema, os ingleses e norte-americanos, nada dizem a respeito dessa origem. Desse modo, em relação às concepções adotadas sobre a questão, de modo geral, ingleses e norte-americanos entendem a resiliência como "resistência ao estresse", enquanto brasileiros e pesquisadores falantes de línguas latinas têm uma concepção que entende a resiliência ora como resistência ao estresse e ora como associada a processos de recuperação e superação de abalos emocionais causados pelo estresse.

Entre os diversos especialistas em resiliência do fim do século 20 (considerando o campo do desenvolvimento humano), como por exemplo, Masten (1999), Kaplan (1999) e Luthar et al (2000), Infante (2005) esclarece que há acordo de que existem 2 gerações de pesquisadores sobre a temática: 
a) A primeira (anos 1970): cujo centro do debate está em investigar os indivíduos em situação de risco social que se adaptam positivamente, mesmo em condições adversas;

b) A segunda (anos 1990): passa a incorporar ao enfoque da primeira geração o estudo da "dinâmica" entre os fatores que situam-se na base da adaptação resiliente.

Desse modo, adentrando ao século 21, a resiliência assume conotações de um processo dinâmico, em que as influências do ambiente e do indivíduo interatuam em uma relação recíproca que permite à pessoa se adaptar, apesar da adversidade (Infante, 2005). Para esta autora, a maioria dos pesquisadores pertencentes a essa geração, simpatiza com o modelo ecológico-transacional de resiliência ${ }^{1}$ que consiste em o indivíduo estar imerso numa ecologia determinada por diferentes níveis, que atuam entre si, exercendo uma influência direta em seu desenvolvimento humano. Os níveis que formam o marco ecológico são: o individual, o familiar, o comunitário (vinculado aos serviços sociais) e o cultural (vinculado aos valores sociais).

Ao decifrar esses processos dinâmicos de interação entre os diferentes níveis do modelo ecológico, poder-se-á entender melhor o processo imerso na resiliência. Consequentemente, o desafio dessa geração de pesquisadores é o de identificar os processos da base da adaptação resiliente que permitirá avançar na teoria e na pesquisa, além de possibilitar a criação de estratégias programáticas dirigidas a promover resiliência e qualidade de vida. Para Infante (2005), é preciso distinguir 3 componentes essenciais que devem estar presentes no conceito de resiliência para a segunda geração de pesquisadores:

1) a noção de adversidade, trauma, risco ou ameaça ao desenvolvimento humano;

2) a adaptação positiva ou superação da adversidade;

3) o processo que considera a dinâmica entre mecanismos emocionais, cognitivos e socioculturais que influem no desenvolvimento humano.

As pesquisadoras Deslandes \& Junqueira (2003) apresentam um resumo do significado de resiliência para alguns estudiosos (quadro 1) e destacam o fato de que muitos autores definem resiliência de maneira operacional do que conceitual.

Autor (Data) Rutter (1987)

\section{Outras Publicações}

Competência e adaptação da pessoa para ultrapassar com sucesso o estresse e a adversidade. Relacionada a vulnerabilidade e a fatores de proteção, através dos quais há uma mudança na resposta da pessoa frente a uma situação de risco, em um sentido adaptativo.

Cicchetti et al. (1993) Funcionamento competente de indivíduos, apesar de severa adversidade (em um

${ }^{1}$ Baseado no modelo ecológico de Bronfenbrenner, de 1981 


\begin{abstract}
sentido adaptativo)
Herrenkohl et al. Fruto da interação entre influências maturacionais, individuais e ambientais, que (1994) muda de acordo com o ambiente e as situações.
\end{abstract}

Blum (1997)

Capacidade de transcender circunstância difíceis de seu ambiente infantil para tornarem-se adultos de sucesso e funcionais.

Vicente (1998)

Capacidade de se recuperar e de manter um comportamento adaptado após um dano.

Fenômeno psicológico construído a partir da presença de figuras significativas e do estabelecimento de vínculos

Bouvier (1999) Capacidade de sair-se bem e de maneira aceitável pela sociedade, apesar de um estresse ou de uma adversidade que possam comportar um risco grave.

Não é uma vacina contra o sofrimento, nem um estado imutável, mas um caminho a percorrer. "A resiliência não consiste em apagar a página, mas em virá-la"

Cyrulnik (1999) Capacidade de se adaptar a diferentes meios e de superar problemas distintos, construindo-se como sujeito na adversidade. É sistêmica e dinâmica e se dá nas interações entre a pessoa em permanente desenvolvimento, seu ambiente e as pessoas que a cercam.

Guedeney (1999) Manutenção de um processo normal de desenvolvimento apesar de condições difíceis, sendo algo dinâmico e complexo, resultado da interação entre indivíduo e ambiente.

Capacidade, em termos psíquicos, de atribuir significado a uma experiência inicialmente sem sentido, de forma a elaborá-lo e assim poder superá-la.

Haynal (1999)

Lemay (1999)

Capacidade de atribuir significado a um evento traumático

Conjunto de mecanismos individuais e familiares que parecem representar um papel para manter a pessoa em relativa harmonia interior, apesar de importantes traumatismos vividos.

Manciaux (1999) Capacidade de reconstruir. Um continuum que varia com as situações, as etapas do desenvolvimento e os períodos da vida.

Capacidade de sair-se bem, mesmo em situações difíceis ou traumáticas.

Poilpot (1999)

Tomkiewicz (1999)

Vanistendael (1999)

Capacidade de sobreviver, de "dar um salto", apesar das adversidades.

Capacidade de uma pessoa ou de um sistema social de ultrapassar as dificuldades, inclusive as traumáticas. Não é a capacidade de saltar um problemas, mas uma capacidade real de cruzar na direção de outra possibilidade através da dificuldade.

Quadro 1: Resumo do conceito de resiliência por diferentes autores

Fonte: Adaptado de Deslandes \& Junqueira (2003, p. 231)

Diante do apresentado no quadro 1 e suas concepções sobre resiliência, Deslandes \& Junqueira (2003) refazem o discurso vigente sobre resiliência e associam 3 polos temáticos às definições encontradas.

Polo Temático

Polo 1: Processo de adaptação e superação

Polo 2: Fator inato e adquirido

Polo 3: Circunstancial e permanente

\section{Característica}

Indivíduos que lidam com as adversidades conseguem extrair aprendizado, conseguindo adaptar-se ao que se espera pela sociedade e/ou superar os traumas vividos. A capacidade de ser resiliente é própria do ser humano ou é adquirida em virtude das adversidades pelas quais o indivíduo é acometido, ou seja, é construída socialmente?

Apesar de não ser aleatória, a resiliência seria apenas circunstancial? Ou, trata-se de uma ,habilidade desenvolvida que comporá uma ,reserva ${ }^{\text {ee }}$ de proteção para o indivíduo? 
A respeito do Polo 1 - "processo de adaptação e superação", as autoras afirmam que desenvolver resiliência não quer dizer que o indivíduo superou todas as vivências traumáticas, ou seja, não significa que ele é resiliente para toda e qualquer situação. “(...) não podemos falar de indivíduos resilientes, mas de uma capacidade do sujeito de, em determinados momentos e de acordo com as circunstâncias, lidar com a adversidade, não sucumbindo a ela" (p. 229). A capacidade de superação é relativa ao indivíduo em determinado contexto. Já sobre o Polo 2 - "fator inato e adquirido", elas sugerem a possibilidade de se estabelecer no cotidiano a resiliência a partir da ação dos sujeitos em seus contextos familiares e culturais, sendo necessário uma relação de confiança, respeito e apoio.

Para as autoras, no Polo 3 - "circunstancial e permanente", indaga-se o fato da resiliência estar relacionada com a personalidade do indivíduo (permanente), ou seja, a qualquer adversidade ocorrerá resposta de maneira resiliente ou é uma resposta para um momento contraditório dissociado da capacidade de ser resiliente, mas de estar resiliente para enfrentar a situação exposta (circunstancial), ou seja, uma estratégia, um recuso adquirido naquele momento específico.

No que se refere a origem, conceitos, enfoques e características atribuídas à questão da "resiliência", constatam-se que para os pesquisadores da área das ciências sociais aplicadas, o termo resiliência pouco difere da utilização pelas outras ciências. Por exemplo, no caso dos estudos em Administração, a ideia de resiliência refere-se à capacidade de superar, reerguer-se e vencer, que uma organização possui ou desenvolve em situações adversas e/ou de crises (Carvalho, 2009). Apesar da resiliência apresentar um conceito compartilhado pelas várias áreas do conhecimento que inclui a ideia de "superação de adversidades", outros temas associam-se a ela, compondo uma constelação temática (Taboada, Legal \& Machado, 2006).

Para os autores, ao se falar em resiliência, é provável que se associe temas como vulnerabilidade, fatores de risco e proteção, superação, adversidades entre outros conceitos que dão sustentação ao referencial teórico que cerca a teoria em estudo. Todavia, as abordagens que operacionalizarão a resiliência dependem de como cada pesquisador define a constelação temática que a cerca.

\section{METODOLOGIA}

No processo de busca do entendimento dos conceitos chaves da "Resiliência", "Resiliente" e "Turismo", presente na literatura tanto de língua portuguesa como inglesa, 
lançou-se mão do procedimento metodológico denominado de Knowledge Development Process - Constructivist (ProKnow-C) desenvolvido por Leonardo Ensslin, Sandra Ensslin, Rogério Lacerda e Jorge Tasca no ano de 2010, no Laboratório de Metodologias Multicritério em Apoio à Decisão (LabMCDA) da Universidade Federal de Santa Catarina. É importante esclarecer que a pesquisa mostrou um cenário internacional e nacional escasso de referencial que tratasse, ao mesmo tempo, das questões sobre "resiliência" e "turismo". Além disso, existem poucos estudos epistemológicos, como observado por Biggs, Hall \& Stoeckl (2012, p. 646) "the somewhat limited literature on resilience in tourism systems thus far has included only conceptual and qualitative studies on the value of the resilience concept to understanding tourism" e a literatura existente sobre a resiliência e turismo inclui limitadas análises conceituais e qualitativas baseadas nas aplicações em áreas protegidas e em comunidades: "qualitative applications of the of the concept to protected area and community-based tourism" (ibid).

A busca nos artigos utilizando a metodologia ProKnow-C acima mencionada encontrou um total de 1436 artigos. A primeira fase do processo de filtragem consistiu na exclusão dos artigos repetidos. Após essa etapa, foi determinado um número de 1405 artigos. A segunda etapa foi então a leitura do título dos artigos para identificar aqueles que se aproximavam da temática aqui proposta. Ao final desta etapa, foi identificado um total de 221 artigos potenciais. Uma análise mais criteriosa no resumo dos artigos apresentou um total de 22 artigos alinhados com o tema deste artigo. A terceira etapa consistiu na verificação da relevância científica, a partir da quantidade de citações dos artigos potenciais. Para isso, recorreu-se ao Google Acadêmico para identificar a quantidade de citações. Dos 21 artigos, 11 não possuem nenhuma citação e por isso foram retirados do Portfólio Bibliográfico, que foi finalizado com 11 artigos, conforme apresentado no quadro 03.

1. Lima, P. P.; Dorion, H.; Milan, G. S.; Severo, E. A.; Ganzer, P. P.; Olea, P. M. (2014). Interface, empreendedorismo e resiliência: Um estudo de caso ambientado na flytour viagens e turismo ltda. Race: revista de administração, contabilidade e economia, Vol.13(2), pp.391-424.

2. Suzano, J. C. C.; Freitas, M. N. C. (2011). Turismo e Pessoas com Deficiência: Atitudes dos Gestores do Setor Hoteleiro. Gerais: Revista Interinstitucional de Psicologia, Vol.4(1), pp.81-92

3. Siqueira, E. D. (2010) Turismo, imagem e cultura: Representações sociais do Estado e do Poder nos cartões-postais da cidade do Rio de Janeiro. Rosa dos Ventos, Vol.1(0)

4. Teixeira, A. B.; Silva, S. D.; Bernardes, G. Darc. (2013). Patrimônio cultural e turismo sustentável: Expectativas e percepções na gestão turística da cidade de Goiás. Encontros Científicos - Tourism \& Management Studies, Issue 1, pp.17-30 
5. Borodako, K. (2011). Cooperation of small and medium-sized tourism enterprises (SMTES) with tourism stakeholders in the Maopolska region - top management perspective approach. Encontros Científicos Tourism \& Management Studies, Issue 7, pp.24-32

6. Azevedo, P. S.; Romão, M.; Rebelo, E. (2014). Success factors for using ERP (Enterprise Resource Planning) systems to improve competitiveness in the hospitality industry. Encontros Científicos - Tourism \& Management Studies, Issue 10, pp.165-168

7. Statev, V. (2009). Features and significance of the value-based method for quantitative measurement of competitiveness in tourism. Encontros Científicos - Tourism \& Management Studies, Issue 5, pp.52-64

8. Souza, J. A. R.; Baltazar, M.; Lenzi, F. C. (2013). Sobre mudar e ser mudado: o impacto da substituição do gestor na organização. Revista Eletrônica de Administração e Turismo, 01 June, Vol.2(1), pp.169-184

9. Carvalho, F. C. C.; Pimentel, T. D. (2013). Fatores internos condicionantes do planejamento turístico local. Turismo y Desarrollo: Revista de Investigación en Turismo y Desarrollo Local, Vol.6(14)

10. Campodónico, R.; Bertolotti, L. C. (2013). El turismo como construcción social: Un enfoque epistemometodológico. Anuario Turismo y Sociedad, Issue 14

11.Estevão, C. M. S.; Nunes, S. M. M. D. (2015).Fatores de Competitividade Turística: A Área Regional deTurismo do Algarve Pasos: Revista de turismo y patrimonio cultural, Vol.13(4), pp.897-912

Quadro 03: Portifólio Bibliográfico

Fonte: elaboração própria, 2016.

Após a análise bibliométrica nos artigos que compõem o Portifólio Bibliográfico verificou-se que o artigo que apresentou maior quantidade de citação, teve 06 citações e foi o "Success factors for using ERP (Enterprise Resource Planning) systems to improve competitiveness in the hospitality industry". O "Cooperation of small and medium-sized tourism enterprises (SMTES) with tourism stakeholders in the Maopolska region - top management perspective approach" obteve 05 citações. $\mathrm{O}$ periódico "Tourism \& Management Studies" foi o que obteve a maior quantidade de artigos dentro do Portfólio Bibliográfico desse estudo, sendo 04 artigos da sua base de dados. Apesar de 11 artigos estarem compondo o portfólio, não foi encontrado nenhum que estabeleça relação entre resiliência e turismo, tendo como foco a gestão.

A partir dos dados obtidos com o Proknow-C é possível destacar a lacuna existente nas pesquisas entre Turismo e Resiliência: tem-se uma área de pesquisa que se mostra abrangente e muito trabalhada que é o turismo; a resiliência, quando pesquisada individualmente, também apresenta um número significativo de trabalhos publicados; entretanto, quando se conjugam essas áreas, nenhuma pesquisa teórica foi publicada. Dessa forma, este artigo qualitativo faz uma revisão de literatura de maneira descritiva com o intuito de apresentar o tema em questão.

\section{DISCUSSÃO DOS RESULTADOS}




\subsection{A RESILIÊNCIA E O PROCESSO DE GESTÃO NO TURISMO}

A maioria das mudanças que marcaram o século XX são caracterizadas principalmente pela globalização da informação e a competitividade cada vez mais acirrada do mercado, onde qualidade, produtividade, sustentabilidade e resultados efetivos, passaram a ser essenciais as organizações. Como consequência, as pessoas saem da condição estereotipada de geradoras para a de solucionadoras de problemas. A gestão passa a ser uma alternativa na (re)solução dos problemas, sendo uma "substituta" ao planejamento. De acordo com Souza (2010, p. 46) "não obstante, a pretendida (não por todos, felizmente) substituição de planejamento por gestão baseia-se em uma incompreensão na natureza dos termos envolvidos". Planejamento e gestão não são duas nuances distintas da administração. Um complementa o outro na medida em que um busca a situação futura e o outro a ação imediata.

O que se propõe na modernidade nada mais é que a adoção da nova gestão, sendo esta, fruto da parceria público-privado. De acordo com Araújo \& Silvestre (2014), a essa nova gestão é interessante para as duas esferas: a parceria pública "respeita aos políticos que estão legitimados e incumbidos de decidirem sobre quais as políticas públicas a serem adotadas para prosseguirem o interesse da comunidade" (p. 572), ao setor privado é levado em consideração as suas habilidades e conhecimentos uma vez que "as empresas privadas, em geral, apresentam um nível maior de desempenho em comparação com a burocracia pública tradicional" (p. 572).

No turismo essa gestão em parceria pública e privada tende a ser muito positiva. É preciso entender que as atuações não se sobrepõem, mas se complementam. Ao poder público compete a elaboração das políticas, a manutenção da ordem social e do progresso econômico, a salvaguarda do patrimônio natural e cultural entre outras ações que dependem dele para acontecer. Ao privado, cabe levantar demandas, exigir implantações, assistir ações, enfim, corroborar e assumir protagonismos para o desenvolvimento da atividade.

Em relação à resiliência, ela está intrínseca na capacidade do ser humano de se recompor de eventos que fogem ao seu controle e que o deixa vulnerável. Desta forma, ser resiliente é, sobretudo, ser capaz de perpassar um trauma (não se deixando sucumbir a ele) e superá-lo. De maneira geral, a resiliência representa a "capacidade que alguns indivíduos apresentam de superar as adversidades da vida" (Taboada, Legal \& Machado, 2006, p. 105). Apesar da resiliência estar associada a capacidade de recuperação, não se pode afirmar que pessoas que demoram mais tempo para superar adversidades ou até mesmo aquelas que não superam, não são resilientes. Por isso, é preciso que se analise o contexto pelo qual o sujeito 
foi exposto e suas atitudes perante os fatos. Por exemplo: quando um material sofre deformação, imputa-se a essa deformação características específicas, tais como: tempo de exposição, intensidade da "força" aplicada, volume do material etc. Só depois de se analisarem todos os fatores é que se atribui a esse material a característica de "ser resiliente". Assim acontece também com o ser humano. A depender do trauma é que se pode afirmar a sua capacidade de resiliência.

O impacto de um evento que culmina com a adoção de estratégias resilientes apresenta respostas em 3 momentos distintos: o antes, o durante e o depois. Todavia, nem sempre esses eventos acontecem organizadamente. É possível que, em meio a crises, os eventos aconteçam simultaneamente, abrindo precedente para que as respostas também aconteçam dessa forma. A figura 2 apresenta como os eventos acontecem e a forma de resposta aos mesmos.

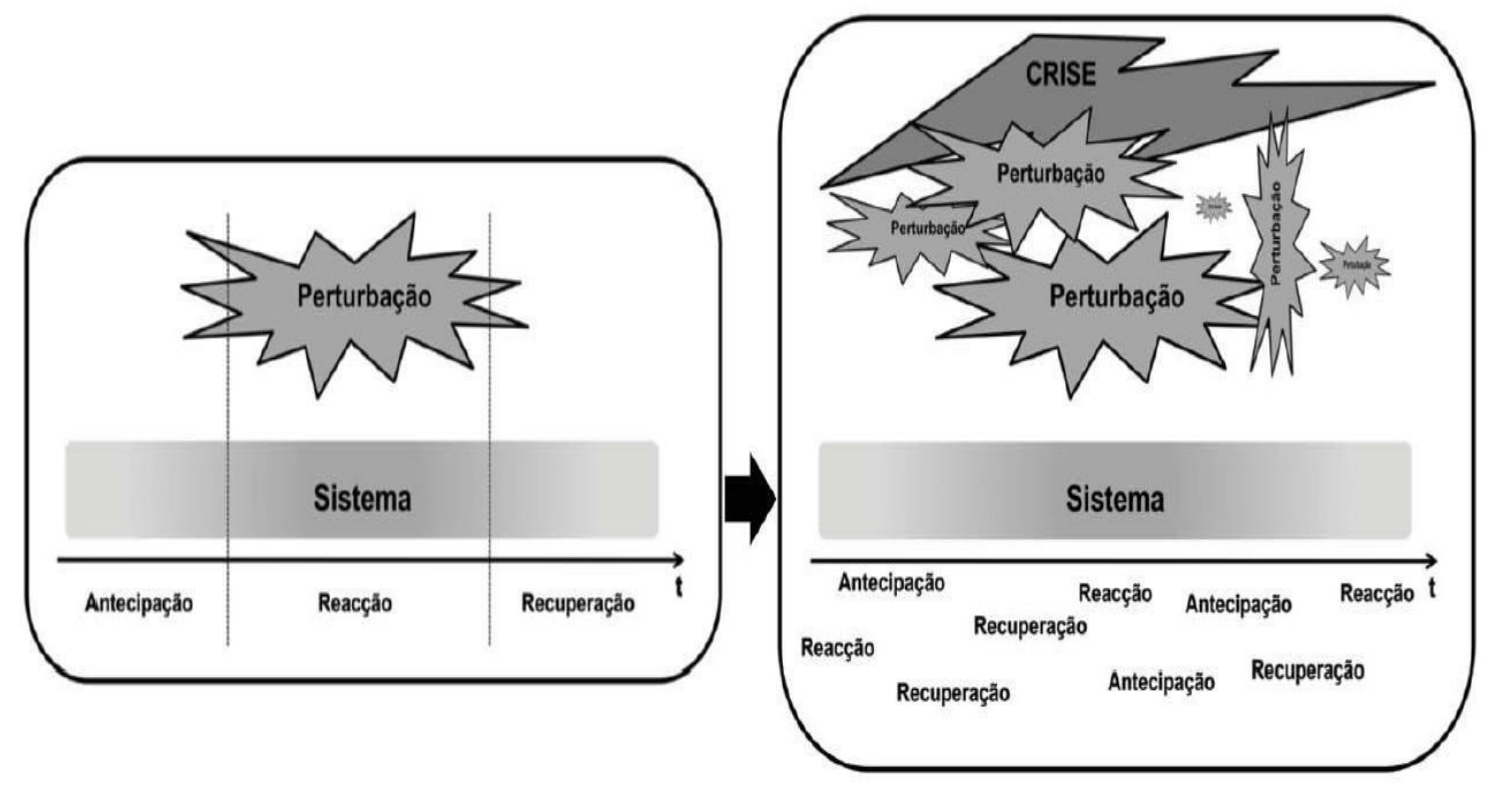

Figura 2: Respostas a perturbações e crises

Fonte: Santos (2009, p. 33).

Antecipação, reação e recuperação são consideradas formas de resposta a eventos perturbadores. Em determinadas situações, essas 3 fases acontecem simultaneamente, exigindo da pessoa (ou do sistema) certa capacidade de enfrentamento. Para a Sociedade Brasileira de Resiliência - SOBRARE - (2016), as "pessoas que apresentam consistente resiliência em seus comportamentos e atitudes, desenvolvem a capacidade de superação ao harmonizarem os pensamentos de modo adequado aos comportamentos, tornando-se mais flexíveis e amadurecidas no enfrentamento das adversidades e desafios". No tocante ao 
turismo e entendendo que eventos perturbadores provocam um estreitamento das relações entre as pessoas do núcleo receptor, turistas e as ações desenvolvidas no seu território (espaço onde se desenvolve o turismo), é preciso elaborar estratégias que solidifiquem e fortifiquem as ligações entre as pessoas e a atividade turística, a fim de garantir a resiliência de ambas. Diante disso, entende-se que é preciso incorporar no processo de planejamento e gestão dos destinos turísticos o seguinte (figura 3):

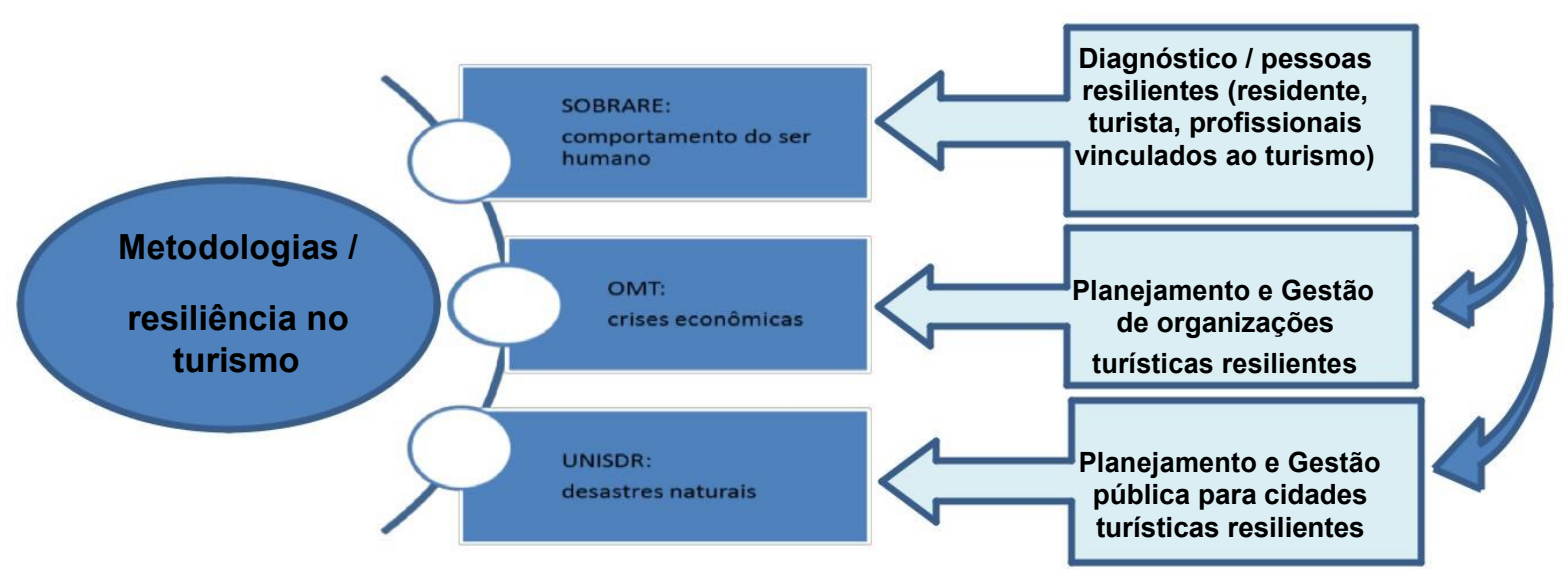

Figura 3: Metodologias sobre resiliência a serem utilizadas no Turismo

Fonte: elaboração própria, 2016.

a) Diagnosticar a capacidade resiliente de um gestor do turismo (metodologia SOBRARE) visando desenvolver características capazes de tornar os sujeitos mais preparados para enfrentar e superar as adversidades;

b) Perseguir as indicações do Tourism Resilience Committee para mitigação de riscos relacionados ao turismo;

c) Diagnosticar a capacidade resiliente de um gestor do turismo (metodologia SOBRARE) visando desenvolver características capazes de tornar os sujeitos mais preparados para enfrentar e superar as adversidades;

d) Incorporar no processo de planejamento e gestão de cidades turísticas as indicações da Campanha da ONU para tornar as cidades resilientes.

Identificar e estudar a constelação temática dos gestores da área de turismo relacionada com a resiliência é fundamental para a tomada de decisão, implementação de estratégias e (re)solução de problemas, pois os gestores são essenciais no gerenciamento da atividade. Para que consigam cumprir com as exigências da função, é imprescindível que eles desenvolvam competências específicas que norteiem o processo de gestão, seja em âmbito 
público ou privado. Portanto, a partir da identificação do modus operandi do gestor, saber-seá como determinada organização poderá ser conduzida, ficando mais claro quais as ações, as proposições, bem como as posturas a serem adotadas. Isto porque a pressão depositada nos indivíduos e/ou grupos gestores para obtenção de sucesso e concretização das metas no trabalho aumentam as suas vulnerabilidades e, consequentemente, diminui o seu rendimento.

Num campo complexo e dinâmico como o do setor turístico, cabe aos gestores estimularem, flexibilizarem e promoverem o equilíbrio no ambiente de trabalho, bem como na localidade receptora, para o adequado funcionamento, adotando abordagens que privilegiem e promovam um cenário resiliente. Isso deve ser buscado tanto nas organizações públicas quanto nas privadas, sempre pautado em ideais de desenvolvimento, independente da formação do gestor ou da sua área de atuação nos diversos segmentos do turismo. Neste cenário, muitos governos, instituições e entidades passaram a utilizar a "resiliência" em seus documentos orientativos, informativos e/ou explicativos. Tem-se como exemplo a proposta de cidades resilientes das Organizações das Nações Unidas (ONU) e a abordagem resiliente da Sociedade Brasileira de Resiliência (SOBRARE).

Entendendo que para o desenvolvimento do turismo é primordial a superação de adversidades e reconhecendo na figura do gestor um agente responsável por pensar o turismo de maneira regional, integrada e resiliente, bem como para propiciar e garantir o desenvolvimento da atividade, é que essas metodologias para análise da resiliência se tornam primordiais nesse estudo. No documento "Como Construir Cidades Mais Resilientes: Guia para Gestores Públicos Locais”, desenvolvido pela ONU para Redução de Riscos de Desastres [UNISDR], apresenta-se 10 passos essenciais para se construir cidades resilientes e como estes devem ser colocados em prática (UNISDR, 2012). O enfoque prioritário deste documento/guia é a atuação dos governos visando à redução de riscos associados às catástrofes/desastres naturais (como tsunamis, secas e terremotos), tendo sido formatado (inicialmente) para gestores públicos com o objetivo de apoiar as políticas públicas, os processos decisórios e a organização para implantação de atividades de redução de riscos de desastres e de resiliência.

Em relação à gestão de destinos turísticos, é importante ressaltar que esta proposta metodológica se aplica a esta atividade, uma vez que projeta as cidades para suportar as adversidades. Assim, seguir os passos proposto pela ONU, é, sem dúvida, uma forma de utilizar essa perspectiva desde a concepção das cidades até as atividades que vão garantir a sobrevivência das mesmas. Na "abordagem resiliente", o conceito de resiliência se revela como: "a capacidade de aprender a administrar e superar obstáculos, adversidades e situações 
de elevado estresse, a partir da ressignificação das crenças básicas” (SOBRARE, 2016, p. 6). Assim, quanto mais amadurecida em sua resiliência é uma pessoa, maior a sua capacidade de ser flexível, coerente e consistente nas suas conclusões (Barbosa, 2011). Isso a torna mais resistente no enfrentamento das situações adversas, tomando decisões que permitam superar e vencer as adversidades. Para a gestão de destinos turísticos, que envolve as dimensões pública e privada, adotar/incorporar nos processos de gerenciamento o disposto no guia para cidades resilientes da ONU e a abordagem resiliente promovida pela SOBRARE, por exemplo, tornará a gestão do turismo mais preparada para atuar em situações de crises ambientais, sociais, políticas e econômicas.

Levando-se em consideração a atividade de atuação desses gestores, o turismo, é preciso entender que as pressões externas pelas quais a atividade passa, culmina com um retardo da resiliência. Para Cabral (2010, p. 177), em sua análise sobre as zonas costeiras resilientes,

(...) a gestão da resiliência deve ser estabelecida, especialmente, onde ela se mostra mais frequente. Em outras palavras, equivale dizer que nos moradores locais e seus conhecimentos está a maior alternativa de criar equilíbrio entre sistema ecológico e sistema social (...).

Desta forma, a gestão participativa, gestão compartilhada deve buscar a consonância entre os saberes locais e os saberes técnicos, deve articular ideais coletivos, deve trabalhar o enfrentamento a situações adversas utilizando os esforços coletivos e não somente o conhecimento teórico, individual, subjetivo. A capacidade de enfrentamento que falta em um gestor da hotelaria pode sobrar no do setor de restauração. Essa troca gera o equilíbrio necessário para as duas partes serem resilientes, superar situações adversas e seguir sem sucumbir às crises. Esta é à base do turismo com abordagem resiliente. É a base do desenvolvimento do turismo resiliente.

\section{CONSIDERAÇÕES FINAIS}

No mercado turístico globalizado e marcado por relações complexas e dinâmicas, a realidade mundial tem deixado claro que para um destino turístico se manter competitivo é preciso atrelar a sua capacidade de adaptação/superação de crises à habilidade de inovação. Tal condição está intimamente relacionada com a capacidade de planejar e gerir o turismo de modo resiliente, uma vez que há uma crescente preocupação com o risco da disseminação de práticas desordenadas nesta área e suas implicações. Ao mesmo tempo, observa-se um 
aumento no número de investigações científicas que buscam criar estratégias para prevenir as instabilidades da atividade turística, embora essas ainda tenham se mostrado incipientes.

Considerando a gestão de destinos turísticos em tempos de crises ambientais, econômicas, políticas, sociais, religiosas e de relações entre pessoas, cabe aos gestores lançar/adotar estratégias de superação das adversidades e zelar por sua manutenção culminando em resultados positivos para o destino. Neste contexto, faz-se necessário a inserção de abordagens diferentes no planejamento e na gestão do turismo, que possa seguir princípios visando ao desenvolvimento regional com o objetivo de promover: a minimização das vulnerabilidades, prevenção de crises, o respeito mútuo, a promoção e perpetuação da igualdade e justiça social, além da preservação do meio ambiente e da melhoria das condições sociais.

O turismo, por fazer uso da infraestrutura da cidade em sua dinâmica e funcionamento, precisa estar planejado sob a égide dessas propostas para evitar que caminhe em direção oposta ao que está sendo estabelecido no âmbito mundial. Para que o turismo se desenvolva numa perspectiva resiliente, os destinos precisam ter características capazes de auxiliar nesse processo. A necessidade de um ambiente organizacional que seja favorável à realização de um trabalho com o menor nível de estresse é, sem dúvida, um fator prioritário na busca pela adoção de estratégias resilientes por parte dos colaboradores das organizações. A pressão depositada para obtenção de êxito e concretização das metas no trabalho aumenta a vulnerabilidade do profissional e consequentemente diminui o seu rendimento. Entender que um ambiente propício é o verdadeiro caminho, constitui fator prioritário na busca do comprometimento e da resiliência organizacional.

\section{REFERÊNCIAS}

AJONU - Associação de Jovens ONU Brasil (2012). Organização Mundial do Turismo. Recuperado em 20 de março, 2016 de http://ajonu.org/2012/10/17/organizacao-mundial-doturismo-omt/.

Antoniazzi, A. S.; DellÀglio, D. D. \& Bendeira, D. R. (1998). O conceito de coping: uma revisão teórica. Estudos de Psicologia, 3(2), 273-294.

Araújo, J. F. F. E. \& Silvestre, H. C. (2014). As parcerias público-privadas para o desenvolvimento de infraestrutura rodoviária: experiência recente em Portugal. Rev. Adm. Pública, 48(3), 571-593, maio/jun. Rio de Janeiro.

Barbosa, G. S. (2011). Resiliência e enfermagem: caminhos de superação para o estresse. In: Sociedade Brasileira de Resiliência (SOBRARE). Resiliência e enfermagem: caminhos de superação. São Paulo: SOBRARE, caderno 2. 
Biggs, D.; Hall, C. M. \& Stoeckl, N. (2012). The resilience of formal and informal tourism enterprises to disasters: reef tourism in Phuket, Thailand. Journal of Sustainable Tourism, $20(5), 645-665$.

Brandão, J. M.; Mahfoud, M. \& Gianordoli-Nascimento, I. F. (2011). A construção do conceito de resiliência em psicologia: discutindo as origens. Paidéia (Ribeirão Preto), 21(49). Mai/Ago.

Cabral, N. W. S. S. (2010). Zona Costeira Resiliente: um estudo sócioecológico no nordeste paraense. Tese (Doutorado em Desenvolvimento Sócio-Ambiental). Universidade Federal do Pará, Belém. 199 f.

Carvalho, R. (2009). O que é ser resiliente?. Recuperado em 20 de janeiro, 2017, de http://www.administradores.com.br/artigos/negocios/o-que-e-ser-resiliente/33338/.

Deslandes, S. F., Junqueira, M. F. P., (2003). Resiliência e maus tratos à criança. Caderno Saúde Pública, 19(1), 227-235. Jan-fev. Rio de Janeiro.

Esslin, L.; Ensslin, S. R.; Lacerda, R. T. O. \& Tasca, J. E. (2010). ProKnow-C, Knowledge Development Process-Constructivist. Processo técnico com patente de registro pendente junto ao INPI. Brasil.

Francisco, M. V. \& Coimbra, R. M. (2015). Resiliência em si na perspectiva da teoria histórico-cultural. Anais de Coimbra, R. M. \& Morais, N. A. (orgs.). A resiliência em questão: perspectivas teóricas, pesquisa e intervenção. Porto Alegre: Artmed.

Infante, F. (2005). A resiliência como processo: uma revisão da literatura recente. Anais de Melillo, A.; Ojeda, E.N.S. (Eds.). Resiliência: descobrindo as próprias fortalezas. Artmed, São Paulo, 22-38. Recuperado em 13 de junho, 2016, de http://www.larpsi.com.br/media/mconnect_uploadfiles/c/a/cap_01ppplo.pdf.

Kaplan, H. (1999). Toward an understanding of resilience: A critical review of definitions and models. In: Glantz, M.; Johnson, J. (Eds.). Resilience and development: positive life adaptations. New York, Plenum Publishers, 17-84.

Luthar, S.; Cicchetti, D. \& Becker, B. (2000). The Construct of resilience: A critical evaluation and guidelines for future work. Child Development, 71(3), 543-558. Recuperado em 12 de junho, 2016, de http://www.ncbi.nlm.nih.gov/pmc/articles/PMC1885202/.

Masten, A. (1999). Resilience comes of age: Reflections on the past and outlooks for the next generation of researchers. In: Glantz, M.; Johnson, J. (Eds.). Resilience and development: positive life adaptations. New York: Plenum Publishers, 281-296.

Miguel, M. E. G. B. (2012). Resiliência e qualidade de vida dos docentes de enfermagem. Ribeirão Preto. Tese de doutorado apresentada à escola de enfermagem de Ribeirão Preto/USP. Universidade de São Paulo.

Ministério da Integração Nacional (2016). Construindo cidades resilientes. Recuperado em 13 de julho, 2016, de http://www.mi.gov.br/web/guest/cidades-resilientes. 
Ojeda, E. N. S. (2004). Introducción: Resiliencia e subjetividad. Anais de A. Melillo, E. N. S. Ojeda, \& D. Rodríguez (Orgs.). Resiliencia y subjetividad: Los ciclos de la vida. Buenos Aires: Paidós.

Raichelis, R. (2006). Gestão pública e a questão social na grande cidade. Lua Nova, São Paulo, (69), 13-48.

Santos, F. T. (2009). Resiliência estratégica para um desenvolvimento regional sustentável. Revista Portuguesa de Estudos Regionais, (20), 29-40.

SOBRARE, Sociedade Brasileira de Resiliência. (2016). E-book Comportamento resiliente nas organizações. Recuperado em 07 de julho, 2014, de www.sobrare.com.br.

Sordi, A. O.; Manfro, G. G. \& Hauck, S. (2011). O Conceito de Resiliência: Diferentes Olhares. Revista Brasileira de Psicoterapia, 13(2), 115-132.

Souza, M. L. (2010). Mudar a cidade: uma introdução crítica ao planejamento e à gestão urbanos. ( $6^{\mathrm{a}}$ ed.). Rio de Janeiro: Bertrand Brasil.

Taboada, N. G.; Legal, E. J. \& Machado, N. (2006). Resiliência: em busca de um conceito. Revista Brasileira de Desenvolvimento Humano, 16(3), 104-113.

Tavares, J. (2001). A resiliência na sociedade emergente. Anais de Tavares, J. (Org.). Resiliência e educação. São Paulo: Cortez.

Timoshenko, S. P. (1953). History of strength of materials: With a brief account of the history of theory of elasticity and theory of structures. New York: McGraw-Hill. Recuperado em 13 de junho, 2016, de https://books.google.com.br/books?hl=pt$\mathrm{BR} \& 1 \mathrm{r}=\& \mathrm{id}=\mathrm{tkScQmyhsb} 8 \mathrm{C} \& \mathrm{oi}=\mathrm{fnd} \& \mathrm{pg}=\mathrm{PR}$ \&\&ots $=\mathrm{X} 4 \mathrm{irge}$ BEB\&sig=A9xcVF0Vik5iIgKv ZTLNxuaaw2M\&redir_esc $=\mathrm{y} \# \mathrm{v}=$ onepage $\& \mathrm{q} \& \mathrm{f}=$ false.

UNISDR, United Nations International Strategy for Disaster Reduction (2012). Como construir cidades mais resilientes: um guia para gestores públicos locais. Genebra: Nações Unidas.

UNISDR, The United Nations Office for Diseaster Risk Reduction. (2012). Recuperado em 10 de maio, 2016, de http://www.unisdr.org/.

(2016). "Participating Local Government”. Recuperado em 29 de novembro, 2016, de http://www.unisdr.org/campaign/resilientcities/home/cities.

UNWTO (2016). World Tourism Organization. Recuperado em 20 de março, 2016, de http://rcm.unwto.org/en/content/about-us-7. 